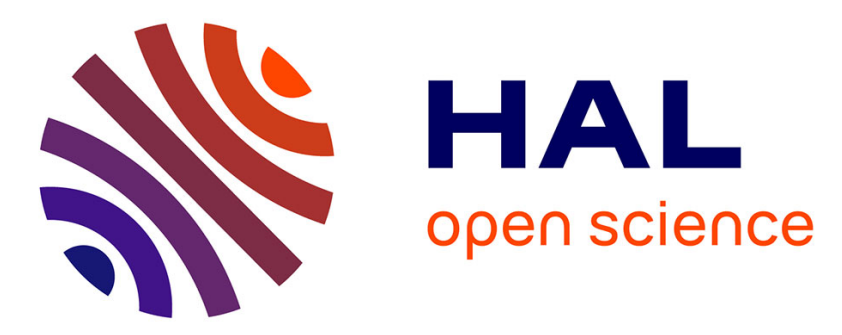

\title{
Business Modeling and Flexibility in Software-Intensive Product Development - A Systematic Literature Review
}

Magnus Wilson, Krzysztof Wnuk

\section{To cite this version:}

Magnus Wilson, Krzysztof Wnuk. Business Modeling and Flexibility in Software-Intensive Product Development - A Systematic Literature Review. 17th Conference on e-Business, e-Services and eSociety (I3E), Oct 2018, Kuwait City, Kuwait. pp.292-304, 10.1007/978-3-030-02131-3_26 . hal02274151

\section{HAL Id: hal-02274151 \\ https://hal.inria.fr/hal-02274151}

Submitted on 29 Aug 2019

HAL is a multi-disciplinary open access archive for the deposit and dissemination of scientific research documents, whether they are published or not. The documents may come from teaching and research institutions in France or abroad, or from public or private research centers.
L'archive ouverte pluridisciplinaire HAL, est destinée au dépôt et à la diffusion de documents scientifiques de niveau recherche, publiés ou non, émanant des établissements d'enseignement et de recherche français ou étrangers, des laboratoires publics ou privés. 


\title{
Business modeling and flexibility in software-intensive product development - A Systematic Literature Review
}

\author{
Magnus Wilson ${ }^{1,2}$ and Krzysztof Wnuk ${ }^{2}$ \\ 1 Ericsson, Karlskona, Sweden, \\ magnus . wilson@ericsson.com \\ 2 Department of Software Engineering, \\ Blekinge Institute of Technology, Karlskona, Sweden \\ krw@bth.se
}

\begin{abstract}
Continuously achieving and maintaining competitive advantage is the critical survival factor for software-intensive product development companies undergoing digitalization transformation. These companies remain uncertain if investments in business modeling is sufficient to cope with rapidly changing business models, technology, and customer demands. We conducted a Systematic Literature Review using the snowballing methodology to explore the effects of business modeling on business flexibility and variability in the realization. Our results confirm a research gap regarding translating desired strategic flexibility into business options that can efficiently and effectively be implemented using software-based variability in the realization. We conclude that more research is needed consolidating business model innovation, experimentation, and operationalization. Building on theories for learning and knowledge creation, we propose a framework for describing change and analyzing strategic, tactical and operational choices in business model experimentation.
\end{abstract}

\section{Introduction}

The inherently flexible nature of software fuels the ongoing digitalization transformation as it allows for rapid changes and adaptations in delivering value to the customers as a response to technology innovation and new business opportunities $[1,2]$. A business model helps to manage and innovate the business toward value creation for all stakeholders [3], by supporting the choices and consequences of these choices in products, business processes, and organizations [4]. Optimizing value creation requires profound understanding of how the implemented business model interacts with products and stakeholders [5].

Software-intensive product development (SIPD) companies have a unique position for efficiently creating value appreciated by all stakeholders. Software is the main component in 1) the tools for implementing and supporting core business processes; 2) developing the software product itself, and; 3) integrating 
the product into the business ecosystem. SIPD companies adapt and integrate their software to the desired business model using business modeling [6].

Business modeling (BM) aims to analyze the business environment and drive change, by adapting and aligning the business strategy with the execution, to create value for all stakeholders $[7,8]$. The literature suggests experimentation [9], collaboration [10], or trial-and-error learning [11] to deal with business model change. The speed of changes in the software business demands increased flexibility between strategy, implementation, and the business model execution [2].

Several prominent authors emphasized the lack of coherence and a clear focus in the business model research $[12,8,13,14]$. In particular, there is a gap in understanding how business modeling interacts with the digital business strategy, and what effects business modeling have regarding selecting, developing, deploying, and monitoring the optimal set of business choices in software products.

This study investigates how flexibility is linked to business modeling for SIPD companies, and if business modeling can bridge the gap between managing business choices and developing variability in the business model realization. Based on the literature review results, we present a summary of the benefits and challenges associated with BM, including reported connections to the flexibility of the business. Next, we synthesize the findings, list trends for BM, and propose a framework to describe change based on changeability and contextual dimensions.

\section{Background and related work}

We base our work on the BM definition by Rohrbeck et al. as "to be a creative and inventive activity that involves experimenting with content, structure, and governance of transactions that are designed to create and capture value" [15]. Rohrbeck et al's. definition supports our investigation of BM for SPID companies in two ways. Firstly, looking at a transaction that creates value as the unit of analysis for a business model [3], it allows for a value-driven business model analysis. Secondly, by introducing the word experimenting, it extends BM to a process of 'translating an idea into execution, test, and change until satisfied,' similar to the agile method of developing software products. However, experimentation requires fast feedback loops between business model planning and execution, so we complement the BM definition with the proposed capabilities needed for BM (Understand and share, Analyze, Manage, and Prospect) [6].

The term flexibility is introduced in different contexts, e.g., strategic flexibility, business flexibility, as a way to managed change. Manufacturing literature suggests that building flexibility entails identifying uncertainty, implementing the appropriate decisions, and monitoring the achieved flexibility [16]. Flexibility in software business models is extensively discussed in literature, e.g., covering pure software business models [17], open source/mixed source [18] and digital options [19], transitions from product-based business models to service-based models [20], or to industrial product-service systems and use models [21-23].

Strategic flexibility (flexible reallocation of resources, changing and adjusting plans and strategies, and maintaining options where needed) is an essential 
topic in business and management literature, e.g., [24,25]. Business flexibility with the ambition to improve business performance is discussed by Manson et al.[24]. They proposed a model where business model flexibility is a function of the network structure, relationship typology and business model focus.

Changeability increases speed and agility by introducing flexibility of strategic choices supported by variability in the realization[23]. Changeability applies to software-based products, their design, production and delivery. and production. We believe that BM will go through a similar evolution as how agile software development changed the ways of working for software development companies (with always working software). Such an evolution will force BM to new representations of information and flexibility, and demand automation tools for effective and efficient planning and execution of business models.

Variability in the realization is discussed under the term Software Product lines (SPL), with a focus on modular architectures and component structures. SPL emphasize creating a platform as a common code base, enabling product realization through variability and configuration management. Building a platform requires long-term investment and locks a company within a single solution for the commodity part of its products. A recent trend is to invest in software ecosystem participation, as a more efficient way of building and maintaining commodity parts of the products [26]. SPL literature mainly focuses on the technical aspects of product development and reuse, rather than business model flexibility.

\section{Methodology}

We considered software-intensive products as the unit of analysis and investigated the following research questions:

RQ1: What benefits and challenges are associated with flexibility in business modeling? We use RQ1 to investigate the contextual setting for business modeling and flexibility.

RQ2: What effects of business modeling related to business flexibility and variability in the realization are reported in the literature? RQ2 addresses how $\mathrm{BM}$ can support flexible business strategies and address the challenge of efficiently implementing the right flexibility in business options. This means deciding the right level of variability in realization.

\subsection{The Snowball methodology}

The Systematic Literature Review (SLR) methodology is based on the guidelines for snowballing literature search proposed by Wohlin [27], outlined below ${ }^{3}$.

\footnotetext{
${ }^{3}$ An Appendix with an illustration of the methodology process including all additional details on the study design are available at https://www.bth.se/wpcontent/uploads/2018/06/SLRBMFlexAppendix.pdf
} 
STEP 1: Design of the literature review. We performed two open-ended interviews (60 minutes each) with an expert in Software Engineering (telecommunication industry with 25 years of experience) and Business management (professor in production management). We asked a question "Does business modeling enable improvements in effectiveness and efficiency for a company? ") to understand the terminology and support creating inclusion criteria (IC) and data extraction properties. We also created a study protocol.

STEP 2: Defining the start set. From the two interviews, we received recommendations about four relevant papers. Next, we searched Google Scholar to derive a collection of definitions and to develop the search strings (SS). We ended up with two search strings ${ }^{4}$. The search string is as follows:

SS1: (business modelling OR business model OR business ecosystem) AND value creation AND strategy SS2: "business modelling" OR "business modeling" OR "business ecosystem") AND "business strategy" AND "value creation" AND ("effectiveness" OR "efficiency" OR "business flexibility" OR modularity OR "variability in realization" OR "governance" OR "multi-business")

Executing SS1 and SS2 (limited to title-abstract-keywords) resulted in 2948 papers. The first author applied the inclusion criteria on titles and abstracts, removing 2378 papers. The remaining 570 papers were put in an excel sheet and duplicates were discarded. The final 477 papers were screened more thoroughly (abstract, introduction, conclusion) by the first and the second authors. We also included one paper [8] recommended by the expert in business management, giving us 10 papers in the start set.

Step 3: Execute Snowballing iterations. Each snowballing iteration started with the first author collecting the references and the citations for each selected paper and applying the exclusion criteria followed by the inclusion criteria. Google Scholar (GS) was used for citations [27]. We used Cohens Kappa in the different iterations for quality assessment, see section 3.2.

We screened 10414 citations and 2958 references in all snowballing iterations. Iteration 1 covered the start set and resulted in 35 selected studies (out of 612 references and 249 citations). Iteration 2 resulted in 2011 references and 10134 citations. Pre-screening (language, title, abbreviated abstract) gave us a remaining 1335 citations to screen. We selected 11 studies in iteration 2. Iteration 3 rendered 313 references and 30 citations, resulting in one new paper selected. Iteration 4 gave no further studies resulting in 57 studies selected for analysis ${ }^{5}$.

\footnotetext{
${ }^{4}$ SS1 uses stemming and SS2 doesn't. Also, "multi-business" was added upon recommendation of industry expert, since executing several business models in parallel is a significant challenge for large SIPD companies
${ }^{5}$ See Appendix
B available
at
https://www.bth.se/wpcontent/uploads/2018/06/SLRBMFlexAppendix.pdf
} 
STEP 4: Data extraction, analysis, and synthesis. The data extraction properties $(\mathrm{EP})^{6}$ were designed and discussed before application. ATLAS $\mathrm{Ti}^{7}$ and Excel were used to keep track of and analyze results, and to synthesize extracted information.

Properties EP1-EP4 were used to analyze the relevance to industry for each papers contribution. Property EP3 (Rigor \& Relevance) was also used for quality assessment. It helped us to evaluate how generalizable the different results were, see section 3.2. Open coding [28] was used for properties EP5-EP9. The extracted data was thematically and narratively analyzed.

The results were iterated in two phases (a) RQ1 and (b) RQ2. For each phase, the first author prepared a summary of listed quotations from all studies. The list was then reviewed against the extracted result, and the first author had to explain a summary of each paper's findings to the reviewer. Both phases were reviewed by the second author.

\subsection{Validity threats}

We adopted the validity guidelines suggested by Runeson [29]. We mitigated the industrial experience bias of the authors by conducting the two initial interviews and iterative refinement of the research questions and also by applying a grounded theory approach [28].

The selected ten papers in the start set are highly heterogeneous and therefore minimize the bias on specific author or terminology. Similarly, we mitigated the author's bias by calculating the Kappa coefficient when selecting the start set papers. The first and the second authors did the Kappa analysis, and the value was $\mathrm{k}=0,566$ and later $\mathrm{k}=0,638$. The Kappa analysis was also performed on $12 \%$ of the studies from the first snowballing iteration with a result of $\mathrm{k}=0.763$.

To mitigate author bias during extraction, six random studies were selected (of the 57 studies) and extracted by the first and second authors. The validation showed a discrepancy of one paper for extraction properties EP1-EP4 and after further discussion full agreement was reached. Also, the results to the RQs (EP5EP9) was iterated in two phases, and each phase was presented by first author before discussed and evaluated by the second author.

Rigor and relevance analysis was applied and adjusted to mitigate potential threats to conclusion validity [30]. The relevance parameter was coded using binary weights $(0,1,2$, and 4 instead of the recommended 0 and 1$)$. We also decided to add property EP4 to specifically address the relevance of a papers content concerning our RQs (since the property EP3 and its relevance aspects only consider the research method and context of a paper). This provided higher resolution when discussing the relevance and comparing the papers.

We minimized potential internal validity threats by following the systematic mapping study guidelines, creating a review protocol and sharing the work associated with data extraction and analysis. Because of the interdisciplinary nature

\footnotetext{
${ }^{6}$ See Appendix C, available at https://www.bth.se/wpcontent/uploads/2018/06/SLRBMFlexAppendix.pdf

7 Software for Qualitative Data Analysis, http://atlasti.com/
} 
of this study, the risk remains that some aspects are underrepresented and other aspects are overrepresented. In particular business model innovation or business process modeling seems to be heavily researched in the business management and the computer science community. However, we decided to focus on the interplay between the strategic intentions, the design of a business model, the realization of it, and the resulting effects on efficiency and effectiveness, rather than details on how individual steps are performed. We addressed this by our choice of a snowballing methodology. We also used grounded theory approach with open coding [28] to harmonize language between the different research fields.

\section{Results}

\subsection{Benefits and challenges associated with business modeling (RQ1)}

We extracted 263 quotes of purpose, benefits, and challenges of business modeling from the identified 57 papers $^{8}$. Quotes of purpose $(\mathrm{P})$ often sets the general context, while quotes of challenges $(\mathrm{C})$ or benefits $(\mathrm{B})$ often are a reflection of how well a solution to a specific problem works. We used open coding to thematically analyze these quotes into the following common areas: 1) Value creation/capture; 2) Assessment (decision control, clarity, visualization); 3) Mind-set and Knowledge; 4) Cost/Revenue; 5) Ends (Vision, goals, and objectives); and 6) Means (Mission, Strategy,Tactics, Directives), Resources) ${ }^{9}$. Also, we identified three primary contexts for BM: 1) Strategy \& planning; 2) Daily operations (executing strategies and plans); and 3) Governance \& communication.

The main purpose for BM is to stay competitive and improve business results. The quotes of purpose are often overlapping and cover a wide variety of more specific topics, like managing specific business aspects (e.g. offerings, market, cost, and revenue), capturing the business logic, over to a holistic nature like 'operationalize strategy', and 'appropriate value from technology'.

We analysed 90 quotes related to the 13 papers ${ }^{10}$ explicitly discussing RQ2 (business flexibility and the variability in the realization). Comparing these 90 quotes with all 263 quotes, the strongest contextual coherence (Purpose, and Benefit or Challenge in the same primary context) ${ }^{11}$ is still found in 'Governance \& communication', but significantly higher ( $45 \%$ vs. $26 \%$ ). It is also interesting to note the shift of quotes from 'Strategy \& planning' towards 'Daily Operations', and from 'Mind-set and Knowledge' towards 'Means'. We believe this is a natural

\footnotetext{
${ }^{8}$ See Appendix D available at https://www.bth.se/wpcontent/uploads/2018/06/SLRBMFlexAppendix.pdf

${ }^{9}$ We use the terms Assessment, Ends, and Means as defined by the Business Motivation Model Version 1.3 (BMM) by Object Management Group, http://www.omg.org/spec/BMM/

${ }^{10}[\mathrm{P} 1]=[31], \quad[\mathrm{P} 3]=[32], \quad[\mathrm{P} 5]=[33], \quad[\mathrm{P} 8]=[10], \quad[\mathrm{P} 9]=[8], \quad[\mathrm{P} 24]=[34], \quad[\mathrm{P} 26]=[21]$, $[\mathrm{P} 27]=[23],[\mathrm{P} 32]=[6],[\mathrm{P} 49]=[7],[\mathrm{P} 52]=[25],[\mathrm{P} 54]=[22],[\mathrm{P} 58]=[24]$

${ }^{11}$ See Appendix E available at https://www.bth.se/wp-
} content/uploads/2018/06/SLRBMFlexAppendix.pdf 
consequence, as the purpose of flexibility is promptly respond to change. This would also be a reasonable explanation for why there are significantly more challenges (36) than benefits (8) reported for these 13 papers, indicating that solutions to achieve flexibility are still immature ${ }^{12}$.

The importance of contextual information is mentioned by seven studies [P8, P17, P18, P20, P25, P51, P59], but no author goes as far as to suggest how to describe the contextual information or represent the information. The underlying purpose reported in the studies is contextually vague, e.g., 'Deal with uncertainty', 'Meeting customerś needs' [P2, P52, P54, P58].

Summarizing the most common challenge for papers explicitly discussing flexibility is how to deal with the dynamics of business models [P5, P9, P32, P49, P54, P58] and most of the quotes on challenges related to the non-existing solutions for governance (representation, simulation, assessment, decision-support, and feedback) of the proposed frameworks and methods. Since governance is not addressed, each individual method or framework may work in its specific context, but taken out of context or combined with other methods to form a solution for an enterprise, they fail to deliver the claimed benefits. The quotes of benefits are mostly unsubstantiated or claimed with limited empirical evidence.

\subsection{Business modeling, business flexibility, and variability in realization (RQ2)}

Looking at the 90 quotes found in the 13 papers explicitly discussing flexibility, we conclude that business flexibility is one of the core aspects in BM [P1, P3, P27, P52, P58]. Succeeding in managing business flexibility increases competitive advantages and performance [P58, P1]. It is essential to understand (and quantify) the value (and cost) of flexibility to optimize the value creation and capture [P27]. Governance (intra-company as well as inter-company) becomes the critical component to facilitate the design of the business model, and link the strategy to the execution of the business model by controlling and aligning the design and invocation of options [P24, P27, P32, P54, P1].

Business flexibility as an option is discussed in the different contextual settings, and on several abstraction levels [P1, P3, P27, P32, P58]. Reim et al. divide options into business model options ( chosen and decided during the business strategy development), and tactical options (comprise all the choices after the business model has been selected) [P3]. Many of these tactical options (contract, marketing, network, and product design) are related to investing in software products and business processes, e.g., integrating new IT systems like Product-Services Systems (PSS).

Mason \& Mousas goes one abstraction level deeper and starts by categorizing options as downstream and upstream relationships, discussing flexibility on three abstraction levels, network (identify), company (develop), and individual (use) [P58]. Upstream has a network-focus with options related to the business

$\overline{12}$ excluding the outlayer [P32] since it contains 25 claimed but unsubstantiated benefits and only 1 challenge 
model architecture (transactional relationship, network influence, and corporate ownership) and tied to the realization of the business by choosing resources, partners, and channels. Downstream has a market-driven focus with options related to the business model focus (customer focus, competitor focus, inter-functional co-ordination) and tied to understanding the customer needs. Woodard et al. discuss options for digital business strategy by introducing the concepts of Design Capital (cumulative stock of designs owned by the company) and Design moves (discrete strategic actions to optimize the Design capital) [P1].

Richter et al. also advocate a modular design and discuss options regarding a systems changeability (adaptability, agility, robustness, flexibility) by embedding flexibility early into system design [P27]. Flexibility must however not be an end in itself, but a conscious compromise between cost and benefit. Osterwalder et al. highlight the critical options managers make, when investing in IT for future strategic business agility, and speculate that business models play an essential role in facilitating such decisions [P32]. Neither of the studies proposes any details on how these concepts could be implemented in an industrial setting to facilitate flexibility with help of software.

Increasing flexibility is discussed in four papers [P3, P5, P8, P26]. Romero \& Molina argue that collaborative networks and experience-centric networks can increase business flexibility and enable agility in dynamic and turbulent markets [P8]. By highlighting the value of co-creation and collaboration across multiple interactive channels, they illustrate how business flexibility can be addressed, but do not bring any further details as to how to manage the flexibility, nor how to measure it. Chew identifies service innovation, with a degree of service variability built into the services, as a way forward to exploit new technologies [P5]. Modularity, platforms, components, and interfaces are a foundation to meet the mass-customization requirements and become faster and more flexible. He concludes that service innovation and service architecture are not enough, but a corresponding modular organization and IT architecture is also required.

Papers [P3, P24, P26] argue that combining products and services into ProductService Systems (PSS) bridges business flexibility with the variability in the realization, and provides individualized, customer-oriented configurations and potential for mass-customization. However, PSS come with a new set of challenges (e.g., industrialization of service offerings) and are highly dependent on the continuous integration of large IT and software solutions into the life-cycle of the business model and organizations [P26].

Osterwalder et al. make propositions how the understanding of a business model, with all its business choices, facilitates and improves goals, the requirement engineering, and the choices of IS/IT infrastructure and applications will lead to more effective and efficient solutions [P32]. However, they do not discuss how the business flexibility is continuously transferred to flexibility in the realization and how these two are aligned.

Summary: Our identified studies offer only partial approaches and solutions (for $\mathrm{BM}$ ) to manage the desired flexibility, and to facilitate pivoting in response 
to disruptive changes in the realization of the business model, e.g., products, organizations, processes, contracts, governance.

Choosing the right options and governance is discussed by seven papers [P1, P24, P27, P32, P49, P54, P58]. Kindström argues that understanding business flexibility is a critical aspect, during the service-based model transition. However, he provides no details and concludes that further research is needed how to industrialize service offering to a larger scale, and how to deal with variability in realization [P24]. Richter et al. discuss flexibility in the context of uncertainty, contracts in use-oriented business models, and IPSS [P27]. They perceive flexibility as the ability to react to changes, and suggest a method to determine the value of flexibility. They discuss 1) Real options for accessing flexibility and 2) Net options value of modularity in the design, and conclude with the need for future research on a combined view on the design of an IPSS and business models. They stress a focus on the IPSS design with the inter-company governance structure, since choosing the right flexibility, is crucial controlling parameter when optimizing value in an IPSS. Similarly, Woodard et al. recommend using a two-dimensional structure of real options and technical debt to facilitate decision-making on options [P1].

Eurich et al. propose a six-step approach to business model innovation based on network thinking [P49], to overcome the tendency of focusing on modelinternal consistency rather than the specific business situation. They argue that in a component-based structure, flexibility and explanatory power are lost, due to the abundant relationships, and often inexplicit dependencies between components and the dynamics of the environment. A vital part of the approach is to understand relevant choices, to make the options explicit, and to visualize relationships between these options. They do not detail how to manage flexibility from all these options and aspects but do recognize governance and early detection as shortcomings. Salgado et al. proposes a framework based on processes, goals, and rules to facilitate and visualize the desired flexibility on IT systems, but conclude their solution needs much research to become robust and scale to industrial settings [P56].

Meier \& Bosslau argue that there is almost no attention in research to the dynamic aspects of business models (flexibility, validation, and implementation) [P54]. They propose a learning feedback system that integrates business model engineering and design, to transfer insights via a business model cockpit back into business model innovation or re-design. They suggest using System Dynamics and diagnostic simulations as a continuous design, validation and implementation of business models, but offer no empirical evidence on the effectiveness or efficiency of their solution.

\section{Discussion}

As Schneider \& Spieth pointed out, the literature provides little evidence that business model innovation does improve dynamic capabilities and strategic flexibility [P52]. They also recommend future research to measure strategic flexibility. 
Our review confirms their viewpoint regarding flexibility and we argue that efficient governance mechanisms focusing on continuously managing consistency and traceability of options, need to be built into both business and software architectures, to contentiously create and manage the required variability in realization. We also believe the concept of changeability as forwarded by Richter et al. [P27], implemented with a governance mechanism between business and software architecture, can play a pivotal role for the operationalization of flexible business models.

Supported by our results [P26, P27, P49, P54], we argue that variability in the realization is an important, but often overlooked aspect of business flexibility which must be an integrated part in the BM analysis and design phases. Business complexity and variability in realization should form a synergy and support conscious investments decision in technology and organization [32]. This puts SIPD companies in a unique position to invest in an optimal flexibility and software architecture for the business model realization. Constraining factors like speed, time-to-market, cost and automation levels, can be solved by software investments in any combination of the three aspects 1) tools for core business processes, 2) the development of SW products itself, and 3) integration of the product into the ecosystem. From the results, we synthesized the following trends:

- experimentation and operationalization of flexible business models to manage the speed of change fueled by the digitalization of the value delivery $[\mathrm{P} 1$, P2, P9, P13, P15, P18, P49]

- changeability and modularity as ways to strategically address all new roles and values via choices to enable faster transitions from strategy to execution [P1, P3, P5, P6, P23, P25, P26, P27]

- need for multifaceted optimization of business models, as fueled by new roles and new values, complementing the more dominant single dimension of cost and revenue [P2, P7, P8, P9, P26, P53]

Our results also reveal an underlying issue of inhomogeneous, non-systematic, contextual descriptions. The importance of "The parts are not the Whole" is argued by Osterwalder et al. [P32] and conclude their paper with "One of the shortcomings in business model literature is that the different authors rarely build on each other. Consequently, business model research as a whole advance more slowly than it could and often stays at a superficial level". Six years later Zott et al. still argue the same [P29], and after an additional three years, Höflinger reaches similar conclusions [P9]. He proposes the following further research directions: 1) further investigation of the business model concept itself, especially with regard to the coherence of the three underlying structures and their interdependencies; 2) considering the dynamics of business model change and innovation requires establishing governance mechanisms to facilitate feedback loops between planning and execution. The first step towards establishing such governance is to understand how change impacts existing business model realization, i.e., describe and document change, so all aspects related to this change can be addressed in the realization (organizations, rules, and IT systems). We illustrate 
this with an example of introducing a new feature in a product at a large organization to improve their agility and decrease time to market by $50 \%$. The initial requirement engineering work by the $\mathrm{R} \& \mathrm{D}$ department resulted in the estimated effort of 2200 person hours. Later, this estimate exploded into a chain of business models and organizational changes affecting own staff, partners, processes, IT systems, changed policies in marketing and advertisement, as well as to change how the product is sold and who should sell it. The total change was estimated to 43000 man-hours over a period of 7 months.

Since the full consequences of a change are greatly unknown until the change is fully implemented, the change often triggers several new changes. The change life-cycle is related to the realization life-cycle, and if new changes occur in already decided changes that are still not (fully) implemented, a rippling effect and propagation of new changes happen, rendering impacts and consequences hard to manage. Therefore, if the speed of changes is faster than the time to implement all changes, a gap grows. As a consequence, the initial business intent might not be fulfilled.

Inspired by the conversation theory by Pask et al. and the knowledge creation process in a business context [35], we speculate that this process of change, when integrated with the process of organizational learning, enables experimentation for a company (rapid and controlled transitions from idea to realization). The need for learning and knowledge transfer is also highlighted by Mason \& Leek to handle dynamic business models [P46].

We, therefore, argue the necessity for having better contextual descriptions of a business model construct. Inspired by the aspects of changeability and ideas presented by Richter et al. on flexibility for use-oriented business models and value-based design [P27], we propose a framework describing and documenting change by four changeability aspects (rows) and five contextual dimensions (columns), see Figure 1. The white oval indicates a change that is introduced, e.g. a new product that requires new functions in marketing (=business function) to reduce time-to-market by $50 \%$ (=agility).

The key characteristic for this framework is to support experimentation and learning while maintaining a practical and efficient level of control (over change) [P9, P15, P18, P22, P36, P51]. That helps an organization to describe how a change propagates and influences the other aspects of changeability and contextual dimensions. Each element in the matrix contains one or several artifacts that are linked and related to real information used in companies. To remain consistent, each matrix element needs to be kept internally, vertically, and horizontally (IVH dimensions) consistent. For each change, the process of maintaining consistency needs to be repeated over the IVH dimensions. Hence axiomatization and efficient information representations are important.

To address the speed of changes challenge, we introduce the Right-time binding concept, defined as a flexibility management function optimized for multidimensional value. Right-time binding allows the invocation of specific options (i.e., choices related to particular change descriptions) to allow runtime decisions rather than during system design. Such flexibility does come at a price [P27], 


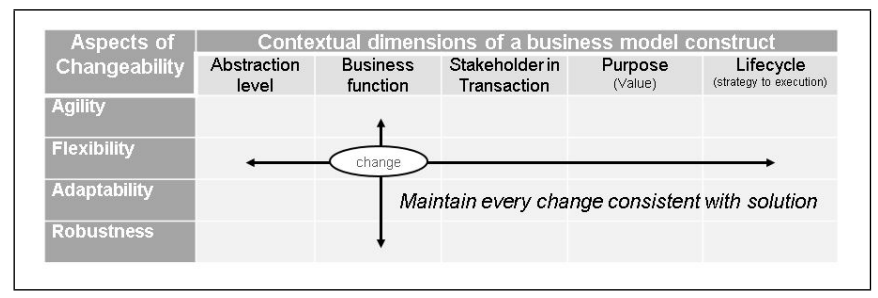

Fig. 1. Framework for describing and documenting change based on changeability aspects and contextual dimensions

and Right-time binding becomes a vital part of the governance mechanisms to simulate and visualize consequences of choices (i.e., changes). It needs to be integrated into the governance mechanisms, the business architecture as well as the software architecture, acting as a bridge between the business model (strategy) and the operationalized business model (execution).

\section{Conclusions}

This systematic literature review explores business modeling and flexibility within the lens of software-intensive product development. Digitalization of software business fuels the diversity of strategic, tactical, and operational choices [36] during efficient business model realizations. The literature provides little evidence that business model innovation utilizes changes to dynamic capabilities to improve strategic flexibility, and our review confirms this viewpoint regarding flexibility. We argue that efficient governance mechanisms focused on continuously managing consistency and traceability of options, need to be built into both the business architecture and the software architecture. Business modeling, supported by efficient information management tools, could become the bridge between the investments in software-enabled variability and the desired strategic flexibility. As the next step, we propose a framework for describing and analyzing change, based on changeability and contextual dimensions.

\section{ACKNOWLEDGMENT}

This work has been supported by the Professional Licentiate of Engineering (PLEng) Pilot Run 2014-2018 in cooperation with Ericsson AB. This work is also supported by the IKNOWDM project (20150033) from KKS in Sweden.

\section{References}

1. C. Matt, T. Hess, and A. Benlian. Digital transformation strategies. Business and Information Systems Engineering, 57:339-343, 2015. 
2. O. Bharadwaj, A.and El Sawey, P. Pavlou, and N. Venkatraman. Digital Business Strategy: Toward a Next Generation of Insights. MIS Quarterly, 37(2):471-482, 2013.

3. Christoph Zott and Raphael Amit. Business Model Design: An activity system perspective. Long Range Planning, 43(2-3):216-226, 2010.

4. R. Casadesus-Masanell and J. Ricart. From Strategy to Business Models and onto Tactics. Long Range Planning, 43(2-3):195-215, 2010.

5. D. Lepak, K. Smith, and S. Taylor. Introduction to special topic forum value creation and value capture: A multilevel perspective. Academy of Management Review, 32:180-194, 2007.

6. A. Osterwalder, Y. Pigneur, and C. Tucci. Clarifying business models: Origins, present, and future of the Concept. Communications of the Association for Information Systems, 15(1):1-25, 2005.

7. M. Eurich, T. Weiblen, and P. Breitenmoser. A six-step approach to business model innovation. Int. Journal of Entrepreneurship and Innovation Management, 18(4):330-348, 2014.

8. N. Höflinger. The business model concept and its antecedents and consequences towards a common understanding. Academy of Management Proceedings: Organization Development \& Change, 2014:1, 2014.

9. H. Chesbrough. Business Model Innovation: Opportunities and Barriers. Long Range Planning, 43(2-3):354-363, 2010.

10. D. Romero and A. Molina. Collaborative networked organisations and customer communities: value co-creation and co-innovation in the networking era. Production Planning and Control, 22(5-6):447-472, 2011.

11. M. Sosna, R. Trevinyo-Rodríguez, and S. Velamuri. Business Model Innovation through Trial-and-Error Learning. Long Range Planning, 43(2-3):383-407, 2010.

12. L. Massa, Ch. Tucci, and A. Afuah. A critical assessment of business model research. Academy of Management Annals, 11, 2016.

13. J. Krumeich, D. Werth, T. Burkhart, and P. Loos. Towards a component-based description of business models: A state-of-the-art analysis. In AMCIS 2012, volume 1, pages 266-277, 2012.

14. C. Zott, R. Amit, and L. Massa. The Business Model: Recent Developments and Future Research. Journal of Management, 37(4):1019-1042, 2011.

15. R. Rohrbeck, L. Konnertz, and S. Knab. Collaborative business modelling for systemic and sustainability innovations. International Journal of Technology Management, 63(1/2):4, 2013.

16. T. Boyle. Manufacturing flexibility: A strategic perspective. Journal of Manufacturing Technology Management, 17:6-211, 2006.

17. M. Schief and P. Buxmann. Business Models in the Software Industry. In 2012 45th HICSS Conference, number 0, pages 3328-3337, 2012.

18. R. Casadesus-Masanell and G. Llanes. Mixed Source. Management Science, 57(7):1212-1230, 2011.

19. V. Sambamurthy, A. Bharadwaj, and V. Grover. Shaping agility through digital options: Reconceptualizing the role of information technology in contemporary firms. MIS Quarterly, 27(2):237-264, 2003.

20. A. Zolnowski and T. Böhmann. Business modeling for services: Current state and research perspectives. In AMCIS 2011 Proceedings - All Submissions. Paper 394., pages 1-8, 2011.

21. H. Meier, R. Roy, and G. Seliger. Industrial Product-Service systems-IPS2. CIRP Annals - Manufacturing Technology, 59(2):607-627, 2010. 
22. H Meier and M Bo. Design and Engineering of Dynamic Business Models for Industrial Product-Service Systems. In CIRP IPS2 Conference, 2012.

23. A. Richter, T. Sadek, and M. Steven. Flexibility in industrial product-service systems and use-oriented business models. CIRP Journal of Manufacturing Science and Technology, 3(2):128-134, 2010.

24. K. Mason and S. Mouzas. Flexible business models. European Journal of Marketing, 46(10):1340-1367, 2012.

25. S. Schneider and PA. Spieth. Business model innovation and strategic flexibility: insights from an experimental research design. International Journal of Innovation Management, 18(6):1-22, 2014.

26. J. Bosch and P. Bosch-Sijtsema. From integration to composition: On the impact of software product lines, global development and ecosystems. Journal of Systems and Software, 2010.

27. C. Wohlin. Guidelines for snowballing in systematic literature studies and a replication in software engineering. In $E A S E$ '14, pages 1-10, 2014.

28. J. Corbin and A. Strauss. Basics of Qualitative Research: Techniques and Procedures for Developing Grounded Theory. SAGE Publications, 2015.

29. P. Runeson and M. Höst. Guidelines for conducting and reporting case study research in software engineering. Emp Soft Eng, 14:131-164, 2009.

30. M. Ivarsson and T. Gorschek. A method for evaluating rigor and industrial relevance of technology evaluations. Empr Soft Eng, 16:365-395, 2011.

31. C. Woodard, N. Ramasubbu, F. Tschang, and V. Sambamurthy. Design capital and design moves: The logic of digital business strategy. MIS Quarterly: Management Information Systems, 37(2):537-564, 2013.

32. W. Reim, V. Parida, and D. Örtqvist. Strategy, business models or tactics - what is product-service systems (PSS) literature talking about? In ICED 2013, volume 4 DS75-04, pages 309-318, 2013.

33. K. Chew. Linking a Service Innovation-Based Framework to Business Model Design. In IEEE 16th Conf. on Business Informatics, pages 191-198. IEEE, 2014.

34. D. Kindström. Towards a service-based business model - Key aspects for future competitive advantage. European Management Journal, 28(6):479-490, 2010.

35. J. Silvander, M. Wilson, K. Wnuk, and M. Svahnberg. Supporting continuous changes to business intents. International Journal of Software Engineering and Knowledge Engineering, 27:1167-1198, 2017.

36. R. Anthony. Planning and control systems; a framework for analysis. Graduate School of Business Administration, Harvard University, Boston, 1965. 